\title{
MicroRNAs in hereditary diffuse gastric cancer (Review)
}

\author{
MAYRA-CECILIA SUÁREZ-ARRIAGA ${ }^{1,2}$, \\ ROSA-MARÍA RIBAS-APARICIO ${ }^{2}$ and MARTHA-EUGENIA RUIZ-TACHIQUÍN ${ }^{1}$ \\ ${ }^{1}$ Medical Research Unit in Human Genetics, Hospital of Pediatrics, National Medical Center XXI Century, \\ Mexican Social Security Institute, Mexico City $06720 ;{ }^{2}$ Department of Microbiology, National \\ School of Biological Sciences, National Polytechnic Institute, Mexico City 11340, Mexico
}

Received March 31, 2016; Accepted June 6, 2016

DOI: 10.3892/br.2016.706

\begin{abstract}
In 2012, gastric cancer (GC) was the third cause of mortality due to cancer in men and women. In Central and South America, high mortality rates have been reported. A total of $95 \%$ of tumors developed in the stomach are of epithelial origin; thus, these are denominated adenocarcinomas of the stomach. Diverse classification systems have been established, among which two types of GC based on histological type and growth pattern have been described as follows: Intestinal (IGC) and diffuse (DGC). Approximately 1-3\% of GC cases are associated with heredity. Hereditary-DGC (HDGC), with $80 \%$ penetrance, is an autosomal-type, dominant syndrome in which $40 \%$ of cases are carriers of diverse mutations of the $\mathrm{CDH} 1$ gene, which encodes for the cadherin protein. By contrast, microRNA are non-encoded, single-chain RNA molecules. These molecules regulate the majority of cellular functions at the post-transcriptional level. However, analysis of these interactions by means of Systems Biology has allowed the understanding of complex and heterogeneous diseases, such as cancer. These molecules are ubiquitous; however, their expression can be specific in different tissues either temporarily or permanently, depending on the stage of the cell. Due to the participation of microRNA in the processes of cellular proliferation, cell cycle control, apoptosis, differentiation and metabolism, these have been indicated to have a role in the development of cancerous processes, finding specific patterns of expression in different neoplasms, including GC, in which the microRNA expression profile is different in samples of non-cancerous versus cancerous tissues. A difference has been observed in the expression patterns of DGC and IGC. However, the role of microRNA in HDGC has not yet been
\end{abstract}

Correspondence to: Dr Martha-Eugenia Ruiz-Tachiquín, Medical Research Unit in Human Genetics, Hospital of Pediatrics, National Medical Center XXI Century, Mexican Social Security Institute, 330 Cuauhtémoc Avenue, Mexico City 06720, Mexico

E-mail: mertachiquin@gmail.com

Key words: hereditary diffuse gastric cancer, microRNA, hsa-miR-9, hsa-miR-92, miR-200 family, let-7 family established. The present study reviews the investigations that describe the participation of microRNA in the regulation of genes CDH1, RHOA, CTNNA1, INSR and TGF- $\beta$ in different neoplasms, such as HDGC.

\section{Contents}

1. Introduction

2. Gastric cancer and heredity

3. Diffuse gastric cancer

4. MicroRNA in HDGC

5. HDGC and genes

6. Conclusion

\section{Introduction}

Cancer is the main cause of mortality in the world (8.2 million mortalities in 2012). Gastric cancer (GC) is estimated to be the fifth most common cancer worldwide, with 952,000 new cases annually. In 2012, GC was the third cause of mortality due to cancer in men and women; $70 \%$ of cases were reported in developing countries, with one-half of these in East Asia. In Central and South America, high mortality rates have been reported (1). In Mexico, according to the statistics of the National Institute of Statistics and Geography, the principal causes of mortalities due to neoplasms are those of the digestive tract organs (32.52 for every 100,000 inhabitants 20 years of age) (2).

GC comprises any malignant neoplasm that originates from the region between the gastroesophageal junction and the pylorus. A total of $95 \%$ of tumors developed in the stomach are of epithelial origin; thus, these are denominated adenocarcinomas of the stomach. The multifocal and polyclonal origin of the tumors renders a morphologically based histological classification complex. However, diverse classification systems have been established (3), among which the study by Lauren (4) described two types of GC based on histological type and growth pattern: Intestinal and diffuse. Intestinal- (or differentiated)-type GC (IGC) is characterized by expansive and localized growth; generally, this type of tumor type localizes in regions where an intestinal metaplasia has developed previously that, in a number of cases, 
is preceded by a precancerous cascade and a prior infection with Helicobacter pylori (5). Diffuse GC (DGC) possesses an infiltrating pattern, is an undifferentiated adenocarcinoma and presents disperse cells with an individual, or group, invasive capacity (3).

\section{Gastric cancer and heredity}

Approximately 1-3\% of GC cases are associated with heredity. Different syndromes have been determined of hereditary-type GC as follows: i) Lynch syndrome; ii) familial adenomatous polyposis; iii) Li-Fraumeni syndrome; iv) Peutz-Jeghers syndrome; v) juvenile polyposis syndrome; and vi) hereditary-DGC (HDGC) (6). The latter is one of the better characterized types, with $80 \%$ penetrance (7). HDGC is an autosomal-type, dominant syndrome in which $40 \%$ of cases are carriers of diverse mutations of the $\mathrm{CDHl}$ gene, which encodes for the cadherin protein (8). The International Gastric Cancer Linkage Consortium (IGCLC), based on diverse studies, has established a direct association between the mutations of the $C D H 1$ gene and DGC heredity; the IGCLC has additionally established various guidelines for its diagnosis, which comprise the following: i) Familial history, which is the presence of $>2$ cases of GC in first- or second-degree consanguinity (one confirmed case in a person aged $>50$ years of age), $>3$ cases of GC in first- or second degree consanguinity, the latter is age-independent; diagnosis of cancer $<40$ years of age, and a personal or familial history of DGC and/or of lobular breast cancer with an age of $<50$ years; ii) histopathological study; iii) detection of the mutation by genetic analysis; and iv) pathogenicity analysis (in vitro and in silico) (7). However, van der Post et al (9) postulated a risk population of individuals with familiar antecedents of two or more cases of bilateral lobular breast cancer, one of these in a relative with confirmed DGC presenting cleft palate and the finding in situ of signet ring cells, whether or not these are propagating.

\section{Diffuse gastric cancer}

Today, DGC comprises one of the most aggressive cancers, without defined molecular markers that permit its accurate and timely diagnosis and/or prognosis. However, $\mathrm{CDH} 1$ gene mutations are associated with the development of HDGC, one-half of cases are negative for these. Thus, investigations are continuing to identify genes that are associated with HDGC. The presence of mutations has been observed in diverse genes, listed as follows: Mutations reported in $R H O A(10,11)$ are associated with the initial stages of cancer and its progression to metastasis; CTNNA1 mutated in HDGC acts as a tumor-suppressor gene (12) and changes in MAP3K6 generate an alteration in inflammation pathways and apoptosis. In addition, it has been found that these are predisposed to develop GC (13) and that changes in the INSR gene (14) exert an effect on the insulin signaling pathway, giving rise to changes in the pattern of glycosylation of the E-cadherin protein, destabilization of cellular membranes and the appearance of a mesenchymal phenotype. Contrary to previously described, the roles of the mutations in the genes FBXO24, DOT1L (14) and TGF- $\beta$ (15) have not yet been studied (Table I). Some of the mutations identified pertain to genes encoding regulatory elements or
Table I. Mutations identified in patients who were negative for mutations in the $\mathrm{CDH} 1$ gene.

\begin{tabular}{lcll}
\hline Gene & Protein encoded & Mutation & Refs. \\
\hline RHOA & GTPase & $\begin{array}{l}\text { c.50G }>\mathrm{A} \\
\text { c. } 14 \mathrm{G}>\mathrm{A}\end{array}$ & $(10,11)$ \\
CTNNA1 & A-cadherin & c.76delGA & $(12)$ \\
& & c.598G $>\mathrm{T}$ & \\
& & c.620T $>\mathrm{G}$ & \\
MAP3K6 & Serine/threonine & c.2837C $>\mathrm{T}$ & $(13)$ \\
& protein kinase & c. $2872 \mathrm{C}>\mathrm{A}$ & \\
DOT1L & Histone & c.2544delC & \\
FBXO24 4 & Protein 24 with F box & c. $242 \mathrm{G}>\mathrm{C}$ & $(14)$ \\
INSR & Insulin receptor & c. $3937 \mathrm{G}>\mathrm{A}$ & $(14)$ \\
TGF- $\beta$ & TGF- $\beta$ & c. $29 \mathrm{C}>\mathrm{G}$ & $(15)$ \\
\hline
\end{tabular}

GTP, guanosine triphosphate; TGF- $\beta$, transforming growth factor- $\beta$.

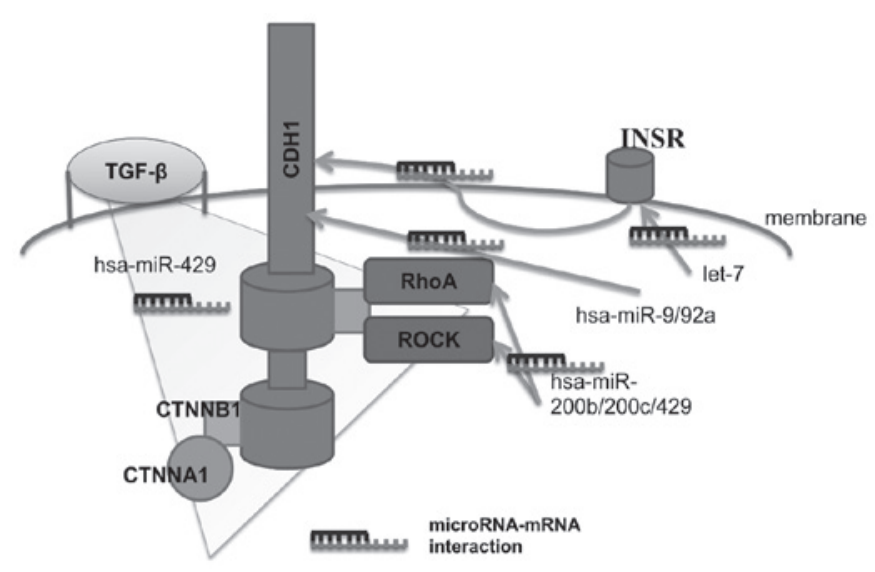

Figure 1. Role of microRNA in the regulation of mutated genes in patients with hereditary diffuse gastric cancer and involvement in the EMT. hsa-miR-9/92a microRNA binds with the 3'-untranslated region of the mRNA of $C D H 1$, impeding its translation. In turn, the expression of the cadherin protein CDH1, in the EMT process can be induced by TGF- $\beta$ and regulated by miR-429. The functioning of the $\mathrm{CDH1}$ protein is associated with elements such as CTNNA1, RhoA and ROCK, which are regulated by the miR-200b subfamily. The gene that regulates the mRNA of INSR is controlled by the let-7 family; the protein encoded by the latter participates in the regulation of the process of E-cadherin glycosylation. EMT, epithelial-mesenchymal transition; TGF- $\beta$, transforming growth factor- $\beta$; ROCK, RhoA kinase; INSR, insulin receptor.

proteins that form complexes with protein E-cadherin; as a consequence of these, the loss of cellular adhesion can present due to deregulation of the complex. However, the majority of the genes postulated require studies of genetic penetrance and pathogeny in order for the genes to be established as markers.

\section{MicroRNA in HDGC}

MicroRNA are non-encoded, single-chain RNA molecules (17-25 nucleotides). These molecules regulate the majority of 
cellular functions at the post-transcriptional level. The regulation carried out by these molecules is complex in that they have $>1$ target mRNA. However, analysis of these interactions by means of Systems Biology, has allowed the understanding of complex and heterogeneous diseases, such as cancer (16).

MicroRNA are transcribed from genes and introns, individually or in groups. These molecules are ubiquitous; however, their expression can be specific in different tissues either temporarily or permanently, depending on the stage of the cell (17). Due to the participation of microRNA in the processes of cellular proliferation, cell cycle control, apoptosis, differentiation and metabolism, these have been indicated in the development of cancerous processes, by observing specific patterns of expression in different neoplasms (18-20), including GC (21-23), in which the microRNA expression profile is different in samples of non-cancerous versus cancerous tissues. A difference has been identified in the expression patterns of DGC and IGC (23). However, the role of microRNA in HDGC has not yet been established. There are studies that describe the participation of microRNA in the regulation of genes CDH1, RHOA, CTNNA1, INSR, and TGF- $\beta$ in different neoplasms $(8,10-15)$.

\section{HDGC and genes}

Beginning with the gene $C D H 1$, in certain studies of microRNA functionality, it has been reported that hsa-miR-9 and hsa-miR-92a are associated with the development of metastasis in esophageal squamous cell carcinoma, their binding with the 3 -untranslated region of the $\mathrm{CDH} 1$ gene, impeding the translation of the latter and induction in the epithelial-mesenchymal transition (EMT) $(24,25)$. The cadherin complex is formed of signaling-charged E-cadherin, catenins and proteins, and the whole complex participates in the EMT. One of the genes comprising the cadherin complex is CTNNA1, which encodes for catenin- $\alpha$. Sun et al (26) observed that there is a difference in the expression profile of the CDH1, CTNNA1, CTNNB1, CD44 and MMP2 genes when EMT is induced, mediated by $T G F-\beta$, which is regulated by hsa-miR-429, a member of the miR-200 family that has been previously associated with the EMT, on regulating zinc finger E-box binding homeobox 1/2 transcriptional repressors. Cadherin-complex signaling-mediated GTPases have regulatory elements, including RhoA and ROCK. In hepatocellular carcinoma, it was demonstrated that these two proteins are targets of the hsa-miR-200b/200c/429 subfamily; all underexpressed in the samples of analyzed tumors. By means of in vivo assays, it was demonstrated that deregulation of the expression profile of this miR-200b subfamily is involved in the EMT and in the development of the metastasis of this carcinoma (27). The glycosylation of E-cadherin mediated by insulin receptors (INSR) is associated with the increase in the capacity of tumor cell invasion, as well as the induction of a mesenchymal phenotype in cancerous cells (28), and it has been observed that the INSR gene is regulated by one of the microRNA suppressor families of tumors involved in the development of numerous neoplasms, such as let-7 (29). The regulation of the MAP3K6, FBXO24 and DOTIL genes mediated by microRNA remains to be elucidated; however, cooperation of the protein DOT1L with c-Myc and an acetyltransferase has been described for activation of the EMT in the initiation and progression of breast cancer to metastasis (30).

\section{Conclusion}

In conclusion, the majority of mutations identified in patients with HDGC, such as hsa-miR-9/92 microRNA, the miR-200 family and the let-7 family, which regulate these genes, are associated with the induction of the EMT (Fig. 1). Thus, investigating the events that trigger this process in patients with HDGC is of significant importance for the establishment of genes and/or of microRNA that can be employed for the diagnosis and prognosis of this neoplasm in patients who are negative for mutations in the $\mathrm{CDH} 1$ gene.

\section{Acknowledgements}

The authors are grateful for the support of the present study from the Coordinación de Investigación en Salud-Instituto Mexicano del Seguro Social and Secretaría de Investigación y PosgradoInstituto Politécnico Nacional-México. MCS-A acknowledges the scholarship and financial support provided by Consejo Nacional de Ciencia y Tecnología (CONACyT no. 576518). The present study constitutes partial fulfillment of the Graduate Program of Master Degree in Sciences, Biomedicine and Molecular Biotechnology, Escuela Nacional de Ciencias Biológicas, Instituto Politécnico Nacional, Mexico City, Mexico.

\section{References}

1. Ferlay J, Soerjomataram I, Dikshit R, Eser S, Mathers C, Rebelo M, Parkin DM, Forman D and Bray F: Cancer incidence and mortality worldwide: sources, methods and major patterns in GLOBOCAN 2012. Int J Cancer 136: E359-E386, 2015.

2. INEGI: Estadísticas a propósito del Día Mundial contra el Cáncer. http://www.inegi.org.mx/saladeprensa/aproposito/2016/cancer2016_0.pdf. Accessed March 6, 2016.

3. Hu B, El Hajj N, Sittler S, Lammert N, Barnes R and Meloni-Ehrig A: Gastric cancer: Classification, histology and application of molecular pathology. J Gastrointest Oncol 3: 251-261, 2012.

4. Lauren P: The two histological main types of gastric carcinoma: Diffuse and so-called intestinal-type carcinoma. An attempt at a histo-clinical classification. Acta Pathol Microbiol Scand 64: 31-49, 1965.

5. Piazuelo MB, Epplein M and Correa P: Gastric cancer: An infectious disease. Infect Dis Clin North Am 24: 853-869, vii, 2010.

6. Tan RYC and Ngeow J: Hereditary diffuse gastric cancer: What the clinician should know. World J Gastrointest Oncol 7: 153-160, 2015.

7. Fitzgerald RC, Hardwick R, Huntsman D, Carneiro F, Guilford P, Blair V, Chung DC, Norton J, Ragunath K, Van Krieken JH, et al; International Gastric Cancer Linkage Consortium: Hereditary diffuse gastric cancer: updated consensus guidelines for clinical management and directions for future research. J Med Genet 47: 436-444, 2010

8. Corso G, Marrelli D, Pascale V, Vindigni C and Roviello F: Frequency of CDH1 germline mutations in gastric carcinoma coming from high- and low-risk areas: Metanalysis and systematic review of the literature. BMC Cancer 12: 8, 2012.

9. van der Post RS, Vogelaar IP, Carneiro F, Guilford P, Huntsman D, Hoogerbrugge N, Caldas C, Schreiber KE, Hardwick RH, Ausems MG, et al: Hereditary diffuse gastric cancer: Updated clinical guidelines with an emphasis on germline $\mathrm{CDH} 1$ mutation carriers. J Med Genet 52: 361-374, 2015

10. Kakiuchi M, Nishizawa T, Ueda H, Gotoh K, Tanaka A, Hayashi A, Yamamoto S, Tatsuno K, Katoh H, Watanabe Y, et al: Recurrent gain-of-function mutations of RHOA in diffuse-type gastric carcinoma. Nat Genet 46: 583-587, 2014. 
11. Wang K, Yuen ST, Xu J, Lee SP, Yan HH, Shi ST, Siu HC, Deng S, Chu KM, Law S, et al: Whole-genome sequencing and comprehensive molecular profiling identify new driver mutations in gastric cancer. Nat Genet 46: 573-582, 2014

12. Majewski IJ, Kluijt I, Cats A, Scerri TS, de Jong D, Kluin RJ, Hansford S, Hogervorst FB, Bosma AJ, Hofland I, et al: An $\alpha$-E-catenin (CTNNA1) mutation in hereditary diffuse gastric cancer. J Pathol 229: 621-629, 2013.

13. Gaston D, Hansford S, Oliveira C, Nightingale M, Pinheiro H, Macgillivray C, Kaurah P, Rideout AL, Steele P, Soares G, et al: Germline mutations in MAP3K6 are associated with familial gastric cancer. PLoS Genet 10: e1004669, 2014.

14. Donner I, Kiviluoto T, Ristimäki A, Aaltonen LA and Vahteristo P: Exome sequencing reveals three novel candidate predisposition genes for diffuse gastric cancer. Fam Cancer 14: 241-246, 2015.

15. Li X, Yue ZC, Zhang YY, Bai J, Meng XN, Geng JS and Fu SB: Elevated serum level and gene polymorphisms of TGF-betal in gastric cancer. J Clin Lab Anal 22: 164-171, 2008.

16. Prasasya RD, Tian D and Kreeger PK: Analysis of cancer signaling networks by systems biology to develop therapies. Semin Cancer Biol 21: 200-206, 2011.

17. Bartel DP: MicroRNAs: Genomics, biogenesis, mechanism, and function. Cell 116: 281-297, 2004.

18. Munker R and Calin GA: MicroRNA profiling in cancer. Clin Sci (Lond) 121: 141-158, 2011.

19. Volinia S, Calin GA, Liu C-G, Ambs S, Cimmino A, Petrocca F, Visone R, Iorio M, Roldo C, Ferracin M, et al: A microRNA expression signature of human solid tumors defines cancer gene targets. Proc Natl Acad Sci USA 103: 2257-2261, 2006.

20. Lu J, Getz G, Miska EA, Alvarez-Saavedra E, Lamb J, Peck D, Sweet-Cordero A, Ebert BL, Mak RH, Ferrando AA, et al: MicroRNA expression profiles classify human cancers. Nature 435: 834-838, 2005

21. Jiang C, Chen X, Alattar M, Wei J and Liu H: MicroRNAs in tumorigenesis, metastasis, diagnosis and prognosis of gastric cancer. Cancer Gene Ther 22: 291-301, 2015.

22. Shrestha S, Hsu SD, Huang WY, Huang HY, Chen W, Weng SL and Huang HD: A systematic review of microRNA expression profiling studies in human gastric cancer. Cancer Med 3: 878-888, 2014.
23. Ueda T, Volinia S, Okumura H, Shimizu M, Taccioli C, Rossi S, Alder H, Liu CG, Oue N, Yasui W, et al: Relation between microRNA expression and progression and prognosis of gastric cancer: A microRNA expression analysis. Lancet Oncol 11: 136-146, 2010.

24. Song Y, Li J, Zhu Y, Dai Y, Zeng T, Liu L, Li J, Wang H, Qin Y, Zeng M, et al: MicroRNA-9 promotes tumor metastasis via repressing E-cadherin in esophageal squamous cell carcinoma. Oncotarget 5: 11669-11680, 2014.

25. Chen Y, Kingham K, Ford JM, Rosing J, Van Dam J, Jeffrey RB, Longacre TA, Chun N, Kurian A and Norton JA: A prospective study of total gastrectomy for CDH1-positive hereditary diffuse gastric cancer. Ann Surg Oncol 18: 2594-2598, 2011.

26. Sun Y, Shen S, Liu X, Tang H, Wang Z, Yu Z, Li X and Wu M: miR-429 inhibits cells growth and invasion and regulates EMT-related marker genes by targeting Onecut 2 in colorectal carcinoma. Mol Cell Biochem 390: 19-30, 2014.

27. Wong CM, Wei L, Au SL, Fan DN, Zhou Y, Tsang FH, Law CT, Lee JM, He X, Shi J, et al: MiR-200b/200c/429 subfamily negatively regulates Rho/ROCK signaling pathway to suppress hepatocellular carcinoma metastasis. Oncotarget 6: 13658-13670, 2015.

28. de-Freitas-Junior JC, Carvalho S, Dias AM, Oliveira P, Cabral J, Seruca R, Oliveira C, Morgado-Díaz JA, Reis CA and Pinho SS: Insulin/IGF-I signaling pathways enhances tumor cell invasion through bisecting GlcNAc N-glycans modulation. an interplay with E-cadherin. PLoS One 8: e81579, 2013.

29. Zhu H, Shyh-Chang N, Segrè AV, Shinoda G, Shah SP, Einhorn WS, Takeuchi A, Engreitz JM, Hagan JP, Kharas MG, et al; DIAGRAM Consortium; MAGIC Investigators: The Lin28/let-7 axis regulates glucose metabolism. Cell 147: 81-94, 2011

30. Cho MH, Park JH, Choi HJ, Park MK, Won HY, Park YJ, Lee CH, Oh SH, Song YS, Kim HS, et al: DOT1L cooperates with the c-Myc-p300 complex to epigenetically derepress CDH1 transcription factors in breast cancer progression. Nat Commun 6: 7821,2015 